\title{
Urological Complications of Gynecological and Obstetric Interventions: Management at the Ignace Deen National Hospital-University Hospital of Conakry (Guinea)
}

\author{
Aissatou Taran Diallo ${ }^{*}$, Yaya Diallo², Bah Oumar Raphiou3, Koudazankpa Esaïe Mahugbé1, \\ Namory Keita ${ }^{4}$, Naby Daouda Camara ${ }^{1}$ \\ ${ }^{1}$ Department of General surgery, Ignace Deen National Hospital, University Hospital of Conakry, Conakry, Guinea \\ ${ }^{2}$ Department of Gynecology and Obstetrics, Ignace Deen National Hospital, University Hospital of Conakry, Conakry, Guinea \\ ${ }^{3}$ Departent of Urology, Ignace Deen National Hospital, University Hospital of Conakry, Conakry, Guinea \\ ${ }^{4}$ Department of Gynecology and Obstetrics, Donka National Hospital, University Hospital of Conakry, Conakry, Guinea \\ Email: *aissatoutaran@gmail.com
}

How to cite this paper: Diallo, A.T., Diallo, Y., Raphiou, B.O., Mahugbé, K.E., Keita, N. and Camara, N.D. (2017) Urological Complications of Gynecological and Obstetric Interventions: Management at the Ignace Deen National Hospital-University Hospital of Conakry (Guinea). Surgical Science, 8, 519-529.

https://doi.org/10.4236/ss.2017.812058

Received: September 7, 2017

Accepted: December 26, 2017

Published: December 29, 2017

Copyright $\odot 2017$ by authors and Scientific Research Publishing Inc. This work is licensed under the Creative Commons Attribution International License (CC BY 4.0).

http://creativecommons.org/licenses/by/4.0/

\section{(c) (i) Open Access}

\begin{abstract}
Introduction: pelvic abdominal surgery may be associated with urological complications requiring reoperation. The aim of this study was to evaluate the urological surgical complications of gynecological and obstetric procedures conducted at the Ignace Deen University Hospital of Conakry in Guinea. Methodology: This was a retrospective, cross-sectional, descriptive study of ten years, from 1 January 2006 to 21 December 2015. Results: Of 14,500 patients hospitalized in the maternity ward during the study period, 31 patients had secondary urological complications during gynecological or obstetric intervention $0.2 \%$ ). The mean age of the patients was 34.77 years (range: 17 to 58 years). The mean duration of hospital stay was 13.29 days (range: 3 to 28 days). Signs of complication were mainly postoperative abdominal pain (64\%, $\mathrm{n}=20)$, vaginal urine leakage $(19.35 \%, \mathrm{n}=6)$ and vaginal bleeding $(9.68 \% \mathrm{n}=$ $3)$. The diagnosis was mainly confirmed by ultrasound $(70.45 \%, \mathrm{n}=31)$. The lesions were primarily ureteric $(77.42 \%, \mathrm{n}=17)$ or on the urethral wounds $(8.12 \%, \mathrm{n}=12)$. Urological complications mostly occurred during hysterectomy $(41.94 \%, \mathrm{n}=13)$ and caesarean section $(32.26 \%, \mathrm{n}=10)$. Repair procedures included uretero-vesical reimplantation $(58.06 \%, \mathrm{n}=18)$, vesico-vaginal fistuloraphy $(22.58 \%, \mathrm{n}=7)$, vesico-uterine fistuloraphy $(12.90 \%, \mathrm{n}=4)$ and temporary ureterostomy $(6.45 \%, \mathrm{n}=2)$. Treatment were successful in $28 \mathrm{pa}-$ tients $(90.32 \%)$ and a lethality of $9.68 \%(\mathrm{n}=3)$ was recorded. Conclusion: Urological surgical complications of obstetric gynecological surgeries were
\end{abstract}


mostly related to hysterectomy and Caesarean section performed by low-skilled surgeons, from peripheral facilities. Prevention measures should include better training and follow-up of practitioners from peripheral health facilities.

\section{Keywords}

Urological Surgical Complications, Hysterectomy, Cesarean Section, Ureteral Injuries, Iatrogenic Urogenital Fistula, Surgical Reoperation

\section{Introduction}

Pelvic abdominal surgery whatsoever may be associated with urological complications that may require the use of reoperation [1] [2]. This is because genital and urinary tracts are anatomically related [3]. While the true incidence of pelvic abdominal surgery related urological complications is difficult to establish, its prevalence has been estimated to range between $0.2 \%$ to $1 \%$ of all gynecologic procedures and pelvic operations [4]. These complications can occur in all countries (including those known as medically advanced). [1] [2]. Often, the revealing clinical signs include oligoanuria, urinary incontinence or lumbar pain [5]. Studies have incriminated surgical interventions that include caesarean section, hysterectomy or myomectomy [3] [5]. The treatment of such injuries requires knowledge of the anatomy of the pelvis [4] [5]. However, in developing countries such as Guinea, there is a lack of trained health care worker at peripheral facilities, including surgeons. Therefore, the risk of urological complications during gynecological and obstetric surgeries might be frequent. A previous report by Diallo et al. [6] included only 16 cases over nine years. It is therefore relevant to conduct more research to provide updated information to policy and decision makers. The purpose of this study was to identify the urological surgical complications of gynecological and obstetric surgeries recorded at the maternity hospital of the Ignace Deen hospital of the CHU of Conakry, to describe their management and to evaluate their evolutionary follow-up.

\section{Material and Methods}

Methodology: This was a retrospective, cross-sectional, descriptive study. We reviewed the medical records of patient consecutively admitted to maternity of the Ignace Deen national hospital who developed urological surgical complications during gynecological and obstetrical surgery. The study covered a ten-year period from 1 January 2006 to 31 December 2015. Only complete medical records with surgery report confirming the re-admission of a patient for urological complication following a gynecological and obstetric intervention were included in this study. Data were collected from individual patient records, hospital registers and surgery reports. Data collected included socio-demographic, diagnostic, therapeutic and outcome data. The confidentiality and anonymity of 
patients' individual data were ensured.

\section{Result}

During the study period, 14,500 patients were hospitalized at the maternity of Ignace Deen University Hospital of Conakry, of whom 31 patients $(0.2 \%)$ experienced urological complications secondary to a gynecological or obstetric intervention, as shown in Figure 1.

Patients' ages varied between 17 and 58 years, with a mean of 34.77 years as shown in Figure 2.

The maximum frequency was recorded among patients aged 31 to 40 years, representing 48.39\% in Figure 1.

The socio-professional groups most affected were traders $(38.71 \%, \mathrm{n}=12)$ followed by civil servants $(32.26 \%, \mathrm{n}=10)$ and housewives $(19.36 \%, \mathrm{n}=6)$, according to the Table 1 .

Multiparous and large multiparous women were the most affected categories with respectively $38.71 \%(n=12)$ and $25.81 \%(n=8)$, according to Table 2 .

The main surgical history was caesarean section $(58.06 \%, \mathrm{n}=18)$, myomectomy $(22.58 \%, \mathrm{n}=7)$ and appendectomy $(6.46 \%, \mathrm{n}=2)$, according to Table 3 .

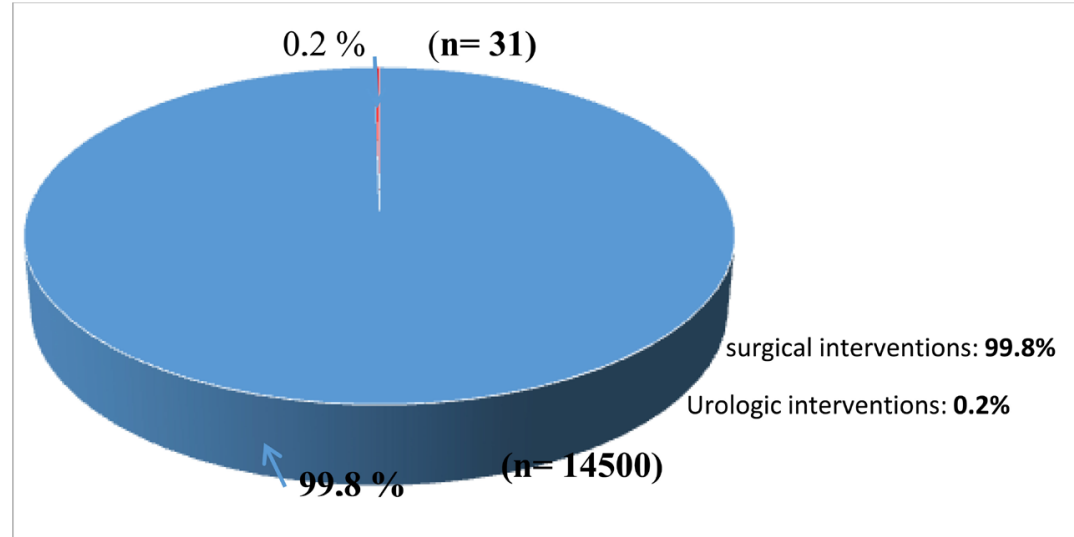

Figure 1. Frequency of urologic complications compared to all surgical procedures.

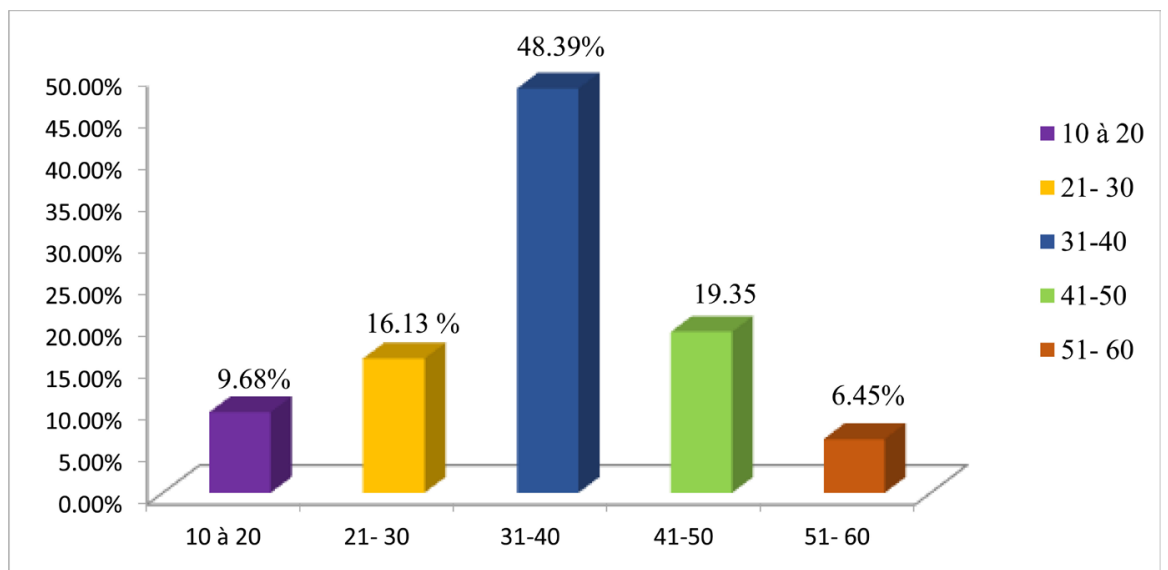

Figure 2. Distribution of patients by age. 
Table 1. Distribution of patients according socio-professional group.

\begin{tabular}{ccc}
\hline Profession & Effective & Percentage \\
\hline Traders & 12 & 38.71 \\
Student & 3 & 9.68 \\
Civil servants & 10 & 32.26 \\
Housewives & 6 & 19.35 \\
Total & 31 & 100 \\
\hline
\end{tabular}

Table 2. Distribution of patients according to parity.

\begin{tabular}{ccc}
\hline Parity & Effective & Percentage \\
\hline Nulliparous & 3 & 9.68 \\
Primiparae & 5 & 16.13 \\
Paucipares & 3 & 9.68 \\
Multiparous & 12 & 38.71 \\
Large multipares & 8 & 25.81 \\
Total & 31 & 100 \\
\hline
\end{tabular}

Table 3. Distribution of patients according to the main surgical history.

\begin{tabular}{ccc}
\hline The main surgical history & Effective & Percentage \\
\hline Caesarean section & 18 & 58.06 \\
Myomectomy & 7 & 22.58 \\
Appendectomy & 2 & 06.46 \\
None surgical history & 4 & 12.90 \\
Total & 31 & 100 \\
\hline
\end{tabular}

The mean admission time, regardless of the type of complication and the type of surgery involved, was 13.29 days (ranging from 3 to 28 days), as shown in Figure 3.

The abdominopelvic pain was the most common discovery circumstance $(64.51 \%, \mathrm{n}=20)$, followed by the leakage of urine from the vagina $(16.12 \%, \mathrm{n}=$ 5) and vaginal bleeding $(9.68 \%, \mathrm{n}=3)$, according to Table 4.

The diagnosis was mainly established using imaging. This included abdominal-pelvic ultrasound $(74.19 \%, \mathrm{n}=23)$, Xray of the abdomen without preparation $(22.58 \%, \mathrm{n}=7)$, Uro-scan $(9.09 \%, \mathrm{n}=4)$ and Intravenous Urography $(4.54 \%, \mathrm{n}=2)$, according to Table 5 .

The surgical procedures that resulted in urological complications included hysterectomy $(45.17 \%, \mathrm{n}=14)$, cesarean section $(32.26 \%, \mathrm{n}=10)$ and myomectomy $(22.58 \%, \mathrm{n}=7$ ), according to Table 6 .

The complications recorded included ureteric wounds $(38.78 \%, \mathrm{n}=12)$, vesico-vaginal fistula $(22.58 \%, \mathrm{n}=7)$, vesico-uterine fistula $(12.90 \%, \mathrm{n}=4)$, uretero-vaginal fistulas and transection of the ureter (respectively $9.68 \%, n=3$ ), according to Table 7 . 


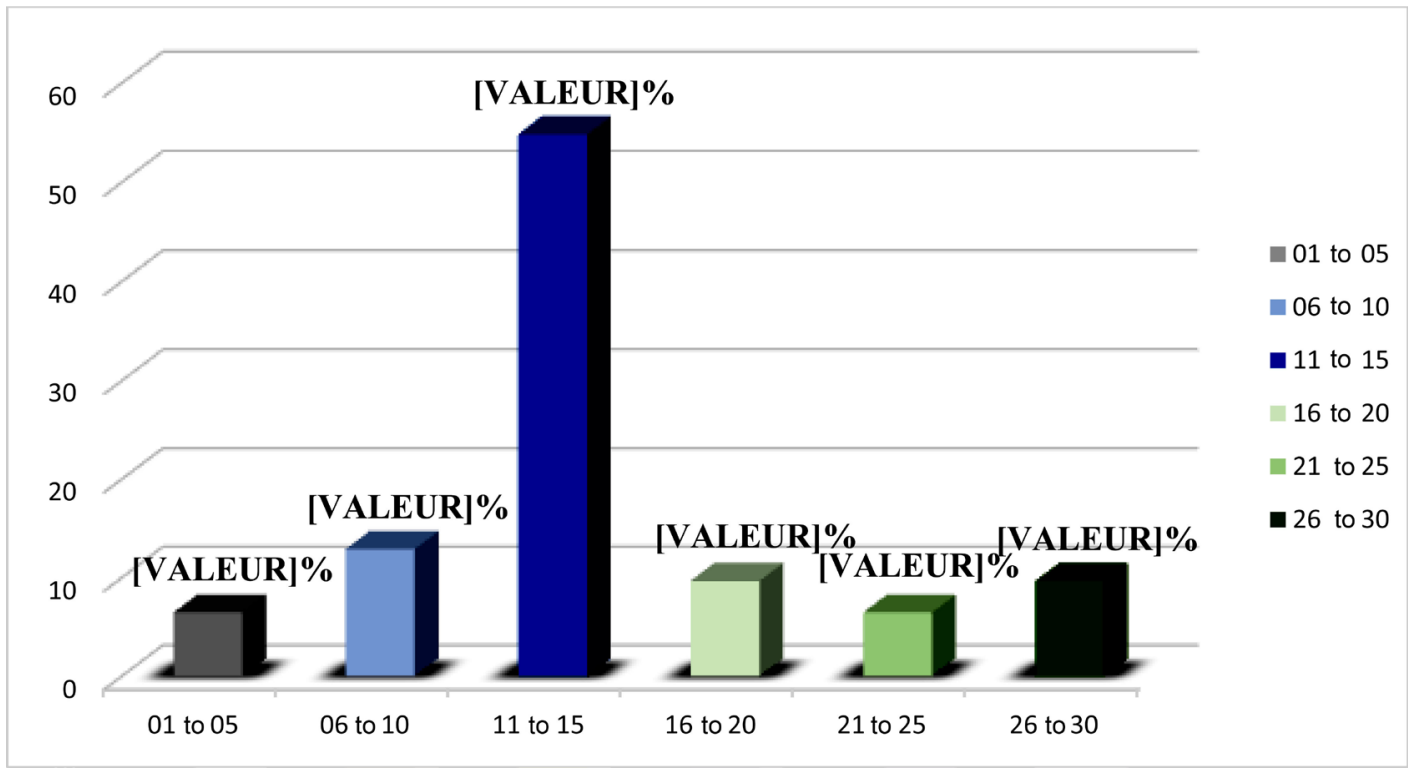

Average length: 13.29 days (ranging from 3 to 28 days).

Figure 3. Distribution according to the mean admission time.

Table 4. Distribution of patients according to the circumstances of discovery of the complication.

\begin{tabular}{ccc}
\hline Circumstances of discovery & Number & Percentage \\
\hline Abdominal-pelvic pain & 20 & 64.51 \\
Leakage of urine to the vulva & 6 & 19.35 \\
Vaginal bleeding & 3 & 9.68 \\
Fever & 2 & 6.45 \\
Total & 31 & 100 \\
\hline
\end{tabular}

Table 5. Distribution of patients according to complementary diagnostic exams conducted.

\begin{tabular}{ccc}
\hline Additional tests & Effective & Percentage \\
\hline Abdominal ultrasound & 23 & 74.45 \\
X-ray of abdomen without preparation & 7 & 15,90 \\
Uro scanner & 4 & 09.09 \\
Intraveinous urography & 2 & 04.54 \\
\hline
\end{tabular}

Table 6. Distribution of urological complications according to gynecological or obstetric intervention.

\begin{tabular}{ccc}
\hline Type of intervention & Effectif & Pourcentage \\
\hline Caesarean & 10 & 32.26 \\
Hysterectomy & 14 & $45.17 \%$ \\
Myomectomy & 7 & 22.58 \\
Total & 31 & 100 \\
\hline
\end{tabular}


Table 7. Types of urologic complications observed.

\begin{tabular}{ccc}
\hline Urologic complications & Effective & Percentage \\
\hline Vesico-vaginal fistula & 7 & 22.58 \\
Uretero-vaginal fistula & 3 & 9.68 \\
Vesico-uterine fistula & 4 & 12.90 \\
Ureteral wounds & 12 & 38.72 \\
Ligation of the ureter & 2 & 6.45 \\
Section of the ureter & 3 & 9.68 \\
Total & 31 & 100 \\
\hline
\end{tabular}

Table 8. Distribution according to the level of qualification of the team of the intervention responsible for the complication.

\begin{tabular}{ccc}
\hline Level qualifying & Effective & Percentage \\
\hline Specialists & 5 & 16.12 \\
Generalists & 10 & 32.25 \\
Non-specialist health & 16 & 51.63 \\
Total & 31 & 100 \\
\hline
\end{tabular}

Table 9. Distribution according to the health facility where the complication occurred.

\begin{tabular}{ccc}
\hline Structure & Effective & Percentage \\
\hline Ignace Deen National Hospital & 3 & 9.68 \\
Communal Medical Center of Ratoma & 6 & 19.35 \\
Maternity of HPC & 13 & 41.94 \\
Communal Medical Center of Matam & 9 & 29.94 \\
Total & 31 & 100 \\
\hline
\end{tabular}

Surgical procedures that resulted in the complications were performed by non-specialist health care workers acting as surgeons or gynecologists including residents $(51.63 \%, \mathrm{n}=16)$, general practitioners $(32.25 \%, \mathrm{n}=10)$, according $\mathrm{Ta}$ ble 8 .

These providers were practicing mostly in peripheral health facilities such as the maternity hospital of Coyah, a city located $45 \mathrm{~km}$ from the city of Conakry $(41.94 \%, n=13)$, the medico-communal hospital of Matam, one of the five municipalities of the city of Conakry $(29.03 \%, n=9)$, according to Table 9.

The treatment was medical and surgical. Most repairs required ureterovesical reimplantation $(58.06 \%, \mathrm{n}=18)$, vesico-vaginal fistula repair $(22.58 \%, \mathrm{n}=7)$, vesico-uterine fistula repair $(12.90 \%, \mathrm{n}=4)$ and temporary ureterostomy $(6.45 \%, \mathrm{n}=2)$, according to Table 10 .

These surgeries were carried out by surgeons (gynécologues and urologists) in mixed teams $(38 \%, \mathrm{n}=12)$ or separately $(62 \%, \mathrm{n}=19)$, according to Table 11 .

The treatment was successful for 28 cases (90.32\%). A lethality of $9.68 \%(\mathrm{n}=$ 
3) was recorded, as shown in Figure 4.

The mean duration of hospital stay was 10.61 days ranging between 4 and 31 days, according to Table 12 .

Table 10. Distribution of patients according to the repair procedure.

\begin{tabular}{ccc}
\hline Realized gesture & Effective & Percentage \\
\hline Vesico-vaginal fistula repair & 7 & 22.58 \\
Vesico-uterine fistula repair & 4 & 12.90 \\
Uretero-vesical reimplantation & 18 & 58.06 \\
Urethrostomy & 2 & 6.45 \\
Total & 31 & 100 \\
\hline
\end{tabular}

Table 11. Distribution of complications according to the qualifications of the surgeon.

\begin{tabular}{ccc}
\hline Team & Effective & Percentage \\
\hline Gynecologists + urologists & 12 & 38 \\
Gynecologists & 19 & 62 \\
Total & 31 & 100 \\
\hline
\end{tabular}

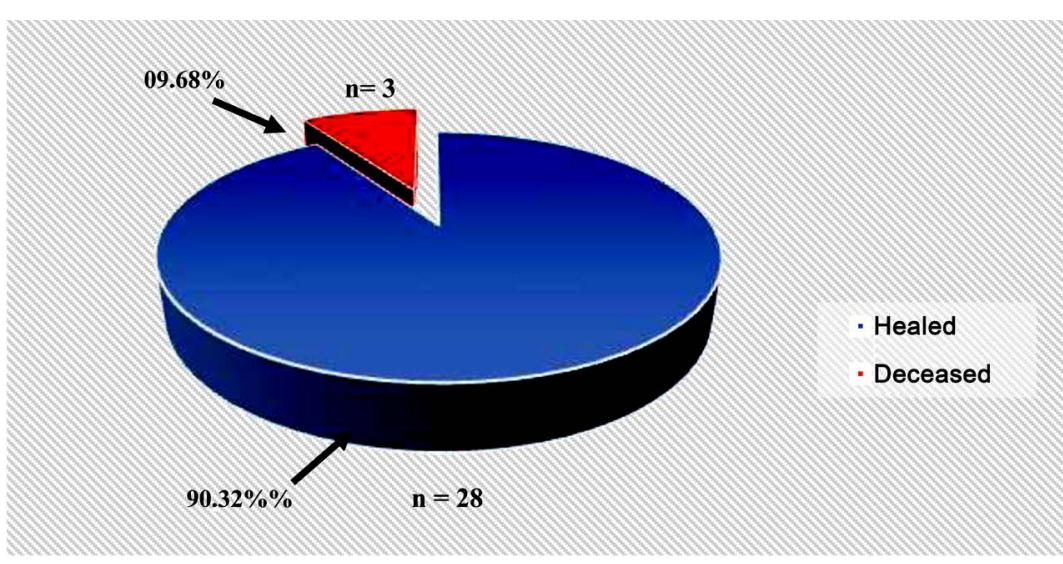

Figure 4. The therapeutic consequences of interventions.

Table 12. Duration of hospital stay after repair surgery.

\begin{tabular}{ccc}
\hline Duration of hospitalization (days) & Effective & Percentage \\
\hline $1-5$ & 4 & 12.90 \\
$6-10$ & 8 & 25.80 \\
$11-15$ & 6 & 19.35 \\
$16-20$ & 1 & 3.23 \\
$21-25$ & 3 & 9.67 \\
$26-30$ & 5 & 16.12 \\
$31-35$ & 4 & 12.90 \\
Total & 31 & 100 \\
\hline
\end{tabular}

Average length: 10, 61 days; Extremes: [4 days; 31 days]. 


\section{Discussion}

During the study period, 31 cases of urological complications secondary to an obstetric gynecological intervention were recorded, representing a hospital frequency of $0.2 \%$. This rate was slightly lower than the $0.3 \%$ reported by Diallo et al. [6] between 1991 and 1999 in the same hospital in Conakry. In 2014, Kpatcha et al. [7] recorder a proportion of $0.9 \%$ of admissions in Lomé, Togo, which was higher that our finding. In their study, Bouya et al. [5] reported that 81 patients were hospitalized for urological complications of gynecologic surgery, representing $3 \%$ of the total admissions. Medically advanced countries are not exempted, despite their mastery of surgical techniques. Visceral complications of pelvic abdominal laparoscopic surgeries have been reported to range from 2.36 per thousand people in Germany to 1.50 per thousand people in the US and 3.25 in France, where laparoscopy urological accidents accounted for $12.4 \%$ of indications for laparotomy [2] This high rate might be due to risk factors that sometimes are linked to previous surgical history, the complexity of the surgical procedure, the lack of experience of the surgeon or non-application of security rules [2] [5].

The high frequency of patients aged between 31 and 50 years found in our study was similar to that of Diallo et al. [6]. It was higher than what was reported by Kpatcha et al. [7] between 20 and 30 years. This result may be explained by the fact that these age groups correspond to the period of the young woman's genital activity. The average age in our study (34.77 years ranging from 17 to 58 years) was lower than the findings from Bouya et al. [5] who reported a mean age of $37 \pm 14.52$ years. While the relatively low age could be related to the period of female genital activity, the older age observed would be due to the long delay in the management of complications and the frequent practice of hysterectomies for benign pathologies in more older women [6] [5].

All socio-occupational strata were represented with a slight predominance for those from informal commercial sector, without any plausible explanation. A possible explanation might be the insufficient level of information to refer to a specialist or a reference health facility able to correctly manage the case. Women engaged in commercial activities are predominant among female population in Guinea. Multiparous and large multiparous were the most affected categories, with $38.71 \%(\mathrm{n}=12)$ and $25.81 \%(\mathrm{n}=8)$. The high frequency of postoperative urological complications in multiparous $(38.71 \%, \mathrm{n}=12)$ and large multiparous $(25.81 \%, \mathrm{n}=8)$ observed in our study has been reported in previous studies [6]. The high frequency observed could be explained by the fact that they had developed probable pelvic adhesions due to several deliveries. The history of abdominal or pelvic surgery could result in dissection difficulties in subsequent intervention and lead to complications. The pelvic inflammatory disease and carcinological surgery might also increase adhesions and alter the usual anatomy, bringing additional technical difficulties in surgery [1] [2] [8] [7]. In our study, the most predominant surgical history was caesarean section $(58.06 \%, \mathrm{n}=18)$ 
and myomectomy $(22.58 \%, \mathrm{n}=7)$.

Abdominal and pelvic pain were the main revealing circumstances in our study (64.51\%), confirming previous findings by Takongmo et al. [9] (88\%) and Diallo et al. [6] (75\%).

The mean time to diagnosis was 13.29 days ranging from 3 to 28 days. These figures were similar to those reported by Bouya et al. [5] who recorded a mean time to diagnosis of 12 days. However, it was lower than the 12.1 week reported in the study by Matani et al. [10].

These delays could be explained by the late discovery of the lesions due to their lack of knowledge in the surgery or to personal resistance of patients to the pain and to the other typical and atypical manifestations of the complication in postoperative. In addition, it could be related to the level of qualification the staff and facility providing the first care.

Hysterectomy was the most common complication in our study with $45.17 \%$, followed by caesarean section $(32.26 \%, \mathrm{n}=10)$ and myomectomy $(19.35 \%$, respectively, $\mathrm{n}=6$ ). Our results corroborate those of Boukerrou et al. [11] showing that hysterectomy was the cause of all urological complications recorded (100\%). This proportion was $76.5 \%$ in the study by Bouya et al. [5] and $62.5 \%$ in that of Diallo et al. [6]. In the study by Oboro et al. [12], hysterectomy (83\%) and salpingo ophorectomie (17\%) were the interventions managed in the department of Surgery, Ile-Ife Osun State, Nigeria.

Kpatcha et al. [7] in Dakar, and Bouya [5] in Brazzaville reported that cesarean section was the intervention resulting in most urological complications with respectively $37.93 \%$ and $61.73 \%$. This was followed by hysterectomy with respectively $34.48 \%$ [7] and 32.10 [5]. However, hysterectomy was the primary cause of ureter's injury [5].

These show that hysterectomy is not a trivial operation. It requires surgical skill and knowledge of anatomy with particular attention during expanded hysterectomies or during difficult dissections [1] [2] [5]. The ureteral injury was observed in $77.42 \%(n=17)$ of the study sample, which is comparable to the $68.75 \%$ reported by Diallo et al. [6]. They were corroborated by the studies conducted by Oboro [12], Kpatcha [7] and Klap [8] for which gynecological and obstetrical surgery accounted for $47 \%$ to $55 \%$ of all wounds ureteral postoperative injuries [7] [8] [12]. Uro genital and uro digestive fistulas were the second type of complication in our study. They were present in the case series published by Sanda et al., in Niger [13] and Kpatcha et al. [7] in Senegal, who noted that the entire section of the ureter, bladder and vaginal fistulas represented $51.72 \%$ of complications $(\mathrm{n}=15)$.

In our study, the intervention that led to the complication was predominantly performed by gynecologists or surgeons, without sufficient qualifications (total $83.88 \%, \mathrm{n}=26)$, practicing in peripheral health (70.97\%). Bouya et al. [5] had also reported that more than half of the complications came from peripheral medical centers $(\mathrm{n}=42 / 81)$. Kpatcha et al. [7] found that the majority of complications were performed by surgeons in training. This may explain why the 
Caesarean, which was considered simple in experienced hands, produced so many complications. The absence in these structures of efficient technical platforms and especially of qualified personnel could explain this observation. For surgery, the inexperience of the operator is a major risk factor for complications [2]. This essential factor takes into account the operating technique, but also the accuracy of its readings and knowledge of the anatomy of the region [2] [5] [7].

The ureteral reimplantation surgery was the most practiced treatment option in our study $(58.06 \%(n=18)$. of the same options were found in studies by Diallo et al. [6] and Bouya et al. [ 5] with a high frequency of ureterovaginal bladder relocations.

The endoscopic and laparoscopic approaches were practiced by some teams [2] [5] [7] [14].

The uro genital fistulas were the second of surgical repairs fistulorraphie with generally favorable results: $75 \%$ for Diallo [6], 90\% for Bouya [5], 98.3\% for Sanda [13] and $100 \%$ for Kpatcha [7]. Surgical treatment was performed by general surgeons, urologists or gynecologists [2] [7] [8] [12]. This elective management made it possible to obtain operative follow-up favorable to rates above $90 \%$ for all the teams. This confirms that the early recognition and management of urological iatrogenic lesions by competent and experienced practitioners would improve the vital and functional prognosis of patients, reduce their hospital stay, and minimize the cost re-surgical intervention.

\section{Conclusion}

Urological complications of gynecological obstetric surgical procedures performed at the Ignace Deen University Hospital were frequent. Hysterectomy and Caesarean section were the most frequent causes, practiced by agents without sufficient qualifications, mainly in peripheral structures. Ureteral lesions were the most frequent. The repair performed at the University hospital by specialists was successful in $90.32 \%$ of the cases. The reduction of these complications will involve the prevention through the qualification training of sufficient interveners, having a perfect knowledge of the anatomy and the principles of good surgical practice, respecting the structures of reference.

\section{References}

[1] Ozdemir, E., Ozturk, U., Celen, S., Sucak, A., Gunel, M., Guney, G., Imamoglu, M.A. and Danisman, A.N. (2011) Urinary Complications of Gynecologic Surgery: Iatrogenic Urinary Tract System Injuries in Obstetrics and Gynecology Operations. Clinical and Experimental Obstetrics \& Gynecology, 38, 217-220.

[2] Hapron, C.C., Querleu, D. and Dubuisson, J.B. (2001) Surgical Complications of Gynecological Laparoscopy in Gynecology. Gynecologie, Obstetrique \& Fertilite, 29, 605-612.

[3] Lee, J.S., Choe, J.H., Lee, H.S. and Seo, J.T. (2012) Urologic Complications Following Obstetric and Gynecologic Surgery. Korean Journal of Urology, 53, 795-799. https://doi.org/10.4111/kju.2012.53.11.795 
[4] Gilmour, D.T., Dwyer, P.L. and Carey, M.P. (1999) Lower Urinary Tract Injury during Gynecologic Surgery and Its Detection by Intraoperative Cystoscopy. Obstetrics \& Gynecology, 94, 883-889

[5] Bouya, P.A., Odzebe, A.W.S. and Otiobanda, F.G. (2011) Urological Complications of Gynecological Surgery. Progres en Urologie, 21, 875-878. https://doi.org/10.1016/j.purol.2011.03.008

[6] Diallo, M.B., Diallo, A.T., Sow, K.B., Guirassy, S. and Diallo, I.S. (2001) Urological Complications of Gynecologic Surgery about 16 Cases. Annals of Neurology, 35, 210-215.

[7] Kpatchaa, T.M., Tenguéa, K., Anoukouma, T., Botchoa, G., Sikpaa, K.H., Fall, P.A., Diao, B. and Diagne, B.A. (2014) Urologic Complications during Pelvic Surgery in aristide le dantec Teaching Hospital in Dakar. African Journal of Urology, 30, 20-25.

http://en.ahau.findplus.cn/?h=articles\&db=edselc\&an=edselc.2-52.0-84920075322

[8] Klap, J., Phe, V., Chartier-Kastler, E., Mozer, P., Bitker, M.-O. and Rouprêt, M. (2012) Etiology and Treatment of Iatrogenic Wounds of the Ureter: Analysis of the Literature. Progres en Urologie, 22, 913-919.

https://doi.org/10.1016/j.purol.2012.05.003

[9] Takongmo, S., Binam, F., Simeu, Ch., Ngassa, P., Kouam, L. and Malonga, E. (2000) Aspects thérapeutiques des péritonites génitales au CHU de Yaoundé (Cameroun). Médecined' Afrique Noire, 47, 19-21.

[10] Matani, Y.S., Bani-Hani, K.E. and Bani-Hani, I.H. (2003) Ureteric Injuries during Obstetric and Gynecologic Procedures. Saudi Medical Journal, 24, 365-368.

[11] Boukerrou, M., Lambaudie, E., Collinet, P., Crepin, G. and Cosson, M. (2004) The Previous Caesarean Section Is a Surgical Risk Factor for Vaginal Hysterectomy? Gynecologie, Obstetrique \& Fertilite, 32, 490-495. https://doi.org/10.1016/j.gyobfe.2004.04.002

[12] Oboro, V.O., Dare, F.O., Fadiora, S.O., Aderounmu, A.O.A., Adeoti, M.L. and Ajadi, A.M. (2002) Ureteric Injuries Following Pelvic Operations. East African Medical Journal, 79, 611-613. https://doi.org/10.4314/eamj.v79i11.8808

[13] Sanda, G., Chipkao, R., Harissou, A., Soumana, A. and Tassiou, E.M. (2016) Iatrogenic Uro Genital Fistula: About 62 Cases and Review of the Literature. African Journal of Urology, 22, 55-60. https://doi.org/10.1016/j.afju.2015.09.007

[14] Karmouni, T., Patard, J.J., Bensalah, K., Manunta, A., Guille, F. and Lobel, B. (2001) Urological Management of Iatrogenic Trauma of the Ureter. Progres en Urologie, 11, 642-646. 